\title{
A longitudinal study on the psychological effects of hemodialysis treatment on primary caregivers of chronic renal failure patients
}

\author{
Jagdish Tekale ${ }^{1}$, N P Patil², Sudhir Gaikwad ${ }^{3}$, Sachin Ghatge ${ }^{4}$, Sagar Kulkarni ${ }^{5}$, Mahesh Kumbhar \\ ${ }^{1}$ Junior Resident, ${ }^{2}$ Professor, ${ }^{3}$ Professor \& HOD, 4,5,6 Assistant Professor, Department of Psychiatry, Bharati Vidyapeeth [Deemed to be \\ University] Medical College and Hospital, Sangli, Maharashtra, INDIA. \\ Email: tekalejagdish@gmail.com
}

Abstract Background: Chronic diseases required a prolonged period of supervision, observation, and predominant care. We often measure the effect of diseases on patients as well as on professional caregivers but tend to forget to determine disease effects on primary caregivers. Taking care of patients suffering from chronic disease produces physical as well as the psychological impact on caregivers. Aim: Assessment of psychological effects of hemodialysis treatment on primary caregivers of chronic renal failure patients. Methods: Present longitudinal study conducted at tertiary care teaching of a hospital. Total 148 primary caregivers of renal failure patients twice interviewed. Out of that; 75 were primary caregivers of patients undergoing pharmacotherapy with hemodialysis (group A) and 73 were those whose patients were on pharmacotherapy alone (group B). The Zarit burden interview tool was used to assess psychological effects. Results: Out of 148 primary caregivers males and females were $72.97 \%$ (108) and $27.07 \%$ (40) respectively. Initially in primary caregivers of group A; $41.3 \%$ and $54.7 \%$ had mild to moderate and moderate to severe type of disease burden while on second interview $57.3 \%$ and $34.7 \%$ responded to have moderate to severe and severe type of disease burden respectively. In group B initially, only $9.6 \%$ informed to have moderate to severe type of disease burden and remaining had either little or mild to moderate type of burden while on follow up interview $49.3 \%$ and $35.6 \%$ had mild to moderate and moderate to severe type of disease burden respectively. Conclusion: Hemodialysis with pharmacotherapy could increase the disease burden on primary caregivers as compared to pharmacotherapy alone.

Key Word: hemodialysis.

\section{*Address for Correspondence}

Dr. Jagdish Tekale, Junior Resident, Department of Psychiatry, Bharati Vidyapeeth [Deemed to be University] Medical College and Hospital, Sangli, Maharashtra, INDIA.

Email: tekalejagdish@gmail.com

Received Date: 06/11/2019 Revised Date: 13/12/2019 Accepted Date: 19/01/2020

DOI: https://doi.org/10.26611/1071331

\begin{tabular}{|l|l|}
\hline \multicolumn{2}{|c|}{ Access this article online } \\
\hline Quick Response Code: & Website: \\
\hline & www.medpulse.in \\
\hline
\end{tabular}

\section{INTRODUCTION}

As per commission on Chronic Illness in USA; chronic diseases are the one which are permanent, caused by non reversible pathology, leaves residual disability, requires rehabilitation and long period of supervision, observation and care. ${ }^{1}$ Chronic kidney disease affects around $10 \%$ population around the world ${ }^{2}$. The prevalence of psychosocial problems in chronic dialysis patients such as anxiety, depression, hostility, and suicidal tendencies are relatively common. ${ }^{3}$ But, Illness are never an isolated life event; like patients suffered, his family and caregivers also endure consequences. Often caregiver receive little attention and the main focus is on the patient. Taking care of patients suffering from chroni disease produces physical as well as the psychological impact on caregivers. We often measure the effect of diseases on patients as well as on professional caregivers but tend to forget to determine disease effects on primary caregivers. With this background present study conducted on primary caregivers, who accompanied chronic renal failure 
patients for the hemodialysis treatment at tertiary care teaching hospital.

\section{OBJECTIVES}

1. Assessment of psychological effects of 'hemodialysis with pharmacotherapy' and 'pharmacotherapy only' treatment on primary care givers of chronic diseases patients

2. Compare the psychological effects of primary care givers of patients of hemodialysis with pharmacotherapy and pharmacotherapy only treatment.

\section{MATERIAL AND METHODS}

Present study conducted after the approval of Institutional and Ethical Committee (IEC). Study design: Observational. Study type: Descriptive Longitudinal Study. Study setting: Hemodialysis unit and Medicine OPD of Bharti Hospital of Bharti Vidyapeeth; (Deemed to be University) Study population: All Primary caregivers who accompanying patients of chronic kidney failure patients for haemodialysis treatment. Primary caregivers who accompanying patients of chronic kidney failure patients for treatment of pharmacotherapy (only) to medicine OPD. Study Period: 18 months (August 2019 to December 2020).

Inclusion criteria's: Primary caregivers of newly diagnosed patients. Primary caregivers of patients who were about to start hemodialysis treatment. Primary caregivers of 18 to 60 years of age.

Exclusion criteria's: Primary caregivers who were not willing to give informed consent. Caregivers who were not engaged as a full time carer of patient. Caregivers who has history of psychiatry morbidity, substance abuse etc. Sampling Method: Simple random sampling method used.

By assuming $50 \%$ prevalence of psychiatric morbidity among primary care givers of chronic renal failure patients. At $95 \%$ confidence level; Z:1.96. $\alpha 5 \%$ and d: 0.13 . The calculated sample size was 57 ; By considering $10 \%$ loss to follow up; $(57+6)=63$ was minimum calculated sample size, which was rounded to 70

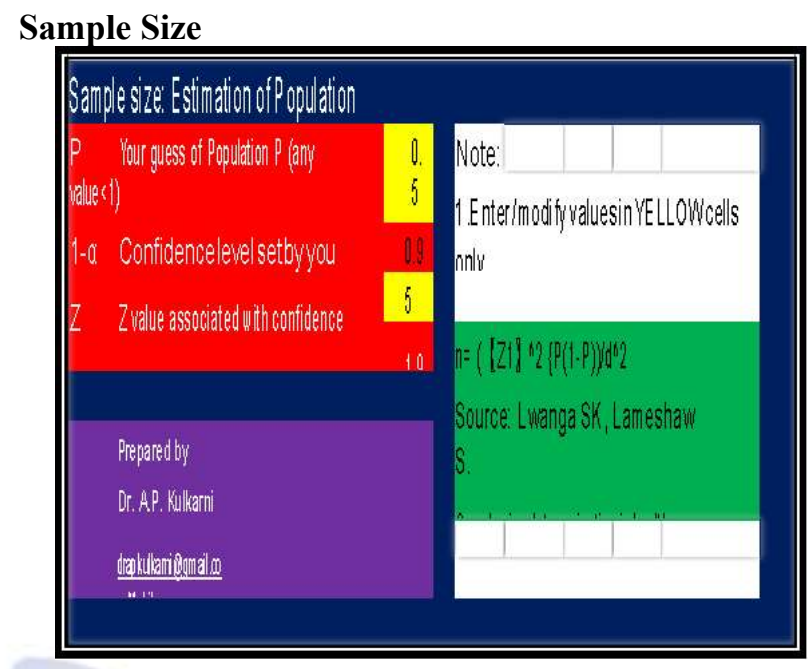

Data collection: After the diagnosis and deciding the line of management by consultant nephrologist; primary caregivers of the chronic renal failure patients were screened as per inclusion and exclusion criteria's. Those who were found to be eligible to participate, were grouped and briefed about the aim and objectives of the present study in their local language.

Group A: Primary caregivers of patients who were on hemodialysis and pharmacotherapy

Group B: Primary caregivers of patients who were on pharmacotherapy only

After assuring the confidentiality of data and obtaining informed consent; primary care givers were twice interviewed according to pre- structured and predetermined questionnaire.

\begin{tabular}{|c|c|c|}
\hline Part 1: Basic Information & Part 2: Psychiatrics disorders & $\begin{array}{c}\text { Part 3:Burden assessment and } \\
\text { Quality of life }\end{array}$ \\
\hline - Socio- demographic data & $\begin{array}{l}\text { - Standard interview including mental status } \\
\text { examination }\end{array}$ & $\begin{array}{l}\bullet \quad \text { Zarit Burden4 } \\
\text { - WHO well being index5 }\end{array}$ \\
\hline
\end{tabular}

\section{Statistical analysis}

Data entry and coding was done in Microsoft excel and SPSS 22.0 statistical software was used for descriptive and inferential statistical analysis 


\section{OBSERVATION AND RESULTS}

In present study; Primary caregivers of patients who were on haemodialysis and pharmacotherapy $\{$ Group I ( $\mathrm{n}=75)\}$, and who were only on pharmacotherapy \{Group II $(\mathrm{n}=73)\}$, after 06 months of first interview were again interviewed.

Table 1: Age and gender wise distribution of the participants $(n=148)$

\begin{tabular}{lcccc}
\hline Sr. No. & $\begin{array}{c}\text { Age group } \\
\text { (Yrs.) }\end{array}$ & Female & Mex & Total \\
\hline 1 & 20 to 25 & 00 & 06 & 06 \\
2 & 26 to 30 & 10 & 02 & 12 \\
3 & 31 to 35 & 10 & 06 & 16 \\
4 & 36 to 40 & 08 & 24 & 32 \\
5 & 41 to 45 & 02 & 22 & 24 \\
6 & 46 to 50 & 04 & 20 & 24 \\
7 & $\geq 51$ Yrs. & 06 & 28 & 34 \\
& Total & $40(27.02 \%)$ & $108(72.97 \%)$ & 148 \\
\hline
\end{tabular}

Chi-square $(\chi 2)$ test: 38.86 , d.f:06, P:0.0001 Significant

\begin{tabular}{ccccc}
\multicolumn{6}{c}{ Chi-square $(\chi 2)$ test: 38.86, d.f:06, P:0.0001 Significant } \\
\hline Sr. & \multicolumn{2}{c}{ Table 2a: Age and Gender wise distribution (Group I) } \\
No. & Age & Female & Male & Total \\
\hline $\mathbf{1 .}$ & $\mathbf{2 0}$ to $\mathbf{2 5}$ & 00 & 03 & 03 \\
$\mathbf{2 .}$ & $\mathbf{2 6}$ to $\mathbf{3 0}$ & 05 & 01 & 06 \\
$\mathbf{3 .}$ & $\mathbf{3 1}$ to $\mathbf{3 5}$ & 05 & 03 & 08 \\
$\mathbf{4 .}$ & $\mathbf{3 6}$ to $\mathbf{4 0}$ & 04 & 12 & 16 \\
$\mathbf{5 .}$ & $\mathbf{4 1}$ to $\mathbf{4 5}$ & 01 & 11 & 12 \\
$\mathbf{6 .}$ & $\mathbf{4 6}$ to $\mathbf{5 0}$ & 02 & 10 & 12 \\
$\mathbf{7 .}$ & $\mathbf{5 1}$ Yrs. & 03 & 15 & 18 \\
& Total & $\mathbf{2 0}$ & $\mathbf{5 5}$ & $\mathbf{7 5}$ \\
\hline
\end{tabular}

Chi-square ( $\chi 2$ ) test:19.81, d.f;06 P:0.003 Significant

Table 2b: Age and Gender wise distribution (Group II)

\begin{tabular}{ccccc}
\hline $\begin{array}{c}\text { Sr. } \\
\text { No. }\end{array}$ & Age & Female & Gender & Male \\
\hline 1. & 20 to 25 & 00 & 03 & Total \\
\hline. & 26 to 30 & 05 & 01 & 03 \\
3. & 31 to 35 & 05 & 03 & 06 \\
4. & 36 to 40 & 04 & 12 & 08 \\
5. & 41 to 45 & 01 & 11 & 16 \\
6. & 46 to 50 & 02 & 10 & 12 \\
7. & $\geq 51$ Yrs. & 03 & 13 & 16 \\
& Total & 20 & 53 & 73 \\
\hline
\end{tabular}

Chi-square $(\chi 2)$ test:19.06, d.f;06 P:0.004 Significant

\begin{tabular}{crrc}
\multicolumn{4}{c}{ Table 3: Age comparison of Group I and II } \\
\hline Age & Group I & Group II & Independent t test \\
\hline Mean \pm Sd. & $42.54 \pm 9.43$ & $42.23 \pm 9.36$ & $\begin{array}{c}\text { P:0.83 Non- } \\
\text { Significant }\end{array}$ \\
\hline
\end{tabular}

Table 4: Comparison of burden of primary care givers of group I

\begin{tabular}{ccc}
\hline Sr. No. & First Interview & Frequency (\%) \\
\hline 1 & No burden & $00(0.0 \%)$ \\
2 & Little or No & $03(4.0 \%)$ \\
3 & Mild to Moderate & $31(41.3 \%)$ \\
4 & Moderate to Sever & $41(54.7 \%)$ \\
5 & Sever & $00(0.0 \%)$ \\
\hline & Total & 75
\end{tabular}




\begin{tabular}{crr}
\hline Sr. & Second (6th month) interview & Frequency (\%) \\
No. & & \\
\hline 1 & No burden & $00(0.0 \%)$ \\
2 & Little or No & $00(0.0 \%)$ \\
3 & Mild to Moderate & $06(8.0 \%)$ \\
4 & Moderate to Sever & $43(57.3 \%)$ \\
5 & Sever & $26(34.7 \%)$ \\
\hline
\end{tabular}

Table 5: Changes in burden of Primary care givers of group I

\begin{tabular}{|c|c|c|c|c|}
\hline \multirow{2}{*}{$\begin{array}{c}\text { Burden T1 } \\
\text { (Initial) }\end{array}$} & \multicolumn{3}{|c|}{ Burden T2 (after 6 months) } & \multirow[b]{2}{*}{ Total } \\
\hline & Mild to Moderate & Moderate to Sever & Sever & \\
\hline Little or No & $02(66.66 \%)$ & $01(33.33 \%)$ & 00 (0.00\%) & 03 \\
\hline Mild to Moderate & $04(12.90 \%)$ & $23(74.19 \%)$ & 04 (12.90\%) & 31 \\
\hline Moderate to Sever & $00(0.00 \%)$ & $19(46.34 \%)$ & $22(53.65 \%)$ & 41 \\
\hline Total & 06 & 43 & 26 & 75 \\
\hline
\end{tabular}

Table 6: Comparison of burden of primary care givers of group II

\begin{tabular}{crr}
\hline Sr. No. & First Interview & Frequency (\%) \\
\hline 1 & No burden & $02(02.7 \%)$ \\
2 & Little or No & $19(26.0 \%)$ \\
3 & Mild to Moderate & $45(61.6 \%)$ \\
4 & Moderate to Sever & $07(09.6 \%)$ \\
5 & Sever & $00(0.00 \%)$ \\
\hline \multicolumn{4}{c}{ Total } & $73(100.0 \%)$ \\
\hline Sr. & Frequency (\%) \\
No. & Second (6th month) interview \\
\hline 1 & No burden & $00(0.00 \%)$ \\
3 & Little or No & $11(15.1 \%)$ \\
4 & Mild to Moderate & $36(49.3 \%)$ \\
5 & Moderate to Sever & $26(35.6 \%)$ \\
\hline & Sever & $00(0.00 \%)$ \\
\hline
\end{tabular}

Table 7: Changes in burden of Primary care givers of group II

\begin{tabular}{ccccc}
\hline \multirow{2}{*}{$\begin{array}{c}\text { Burden T1 } \\
\text { (Initial) }\end{array}$} & \multicolumn{5}{c}{$\begin{array}{c}\text { Burden T2 (after 6 } \\
\text { months) }\end{array}$} \\
\hline No burden & $00(0.00 \%)$ & $02(100.0 \%)$ & $0(0.00 \%)$ & Moderate to Sever \\
Little or No & $06(31.57 \%)$ & $13(68.42 \%)$ & $00(0.00 \%)$ & $\mathbf{0 2}$ \\
Mild to Moderate & $05(11.11 \%)$ & $20(44.44 \%)$ & $20(44.44 \%)$ & $\mathbf{1 9}$ \\
Moderate to Sever & $00(0.00 \%)$ & $01(14.28 \%)$ & $06(85.71 \%)$ & $\mathbf{4 5}$ \\
\hline
\end{tabular}

Table 8A: Changes in burden of Primary care givers of group I with respect to Female Gender

\begin{tabular}{ccccc}
\hline $\begin{array}{c}\text { Burden T1 } \\
\text { (Initial) }\end{array}$ & \multicolumn{4}{c}{ Burden T2 (after 6 months) } \\
Little or No & $02(100.0 \%)$ & $00(0.00 \%)$ & $00(0.00 \%)$ & 02 \\
Mild to Moderate & $01(16.66 \%)$ & $03(50.0 \%)$ & $02(33.3 \%)$ & 06 \\
Moderate to Sever & $00(0.00 \%)$ & $03(25.0 \%)$ & $09(75.0 \%)$ & 12 \\
\hline Total & 03 & 06 & 11 & 20 \\
\hline
\end{tabular}

Chi-square ( $\chi 2)$ test:15.42, d.f:04, P:0.004 Significant 
Table 8B: Changes in burden of Primary care givers of group I with respect to Male Gender

\begin{tabular}{|c|c|c|c|c|}
\hline \multirow[t]{2}{*}{ Burden T1 (Initial) } & \multicolumn{2}{|c|}{$\begin{array}{c}\text { Burden T2 (after } 6 \\
\text { months) }\end{array}$} & \multirow[b]{2}{*}{ Severe } & \multirow[b]{2}{*}{ Total } \\
\hline & Mild to Moderate & Moderate to Sever & & \\
\hline Little or No & $00(0.00 \%)$ & $01(100.0 \%)$ & $00(0.00 \%)$ & 01 \\
\hline Mild to Moderate & $03(12.0 \%)$ & $20(80.0 \%)$ & $02(08.0 \%)$ & 25 \\
\hline Moderate to Sever & $00(0.00 \%)$ & $16(55.17 \%)$ & $13(44.82 \%)$ & 29 \\
\hline Total & 03 & 37 & 15 & 55 \\
\hline
\end{tabular}

Chi-square ( $\chi 2)$ test:11.94, d.f:04, P:0.01 Significant

Table 9A: Changes in burden of Primary care givers of group II with respect to Female Gender

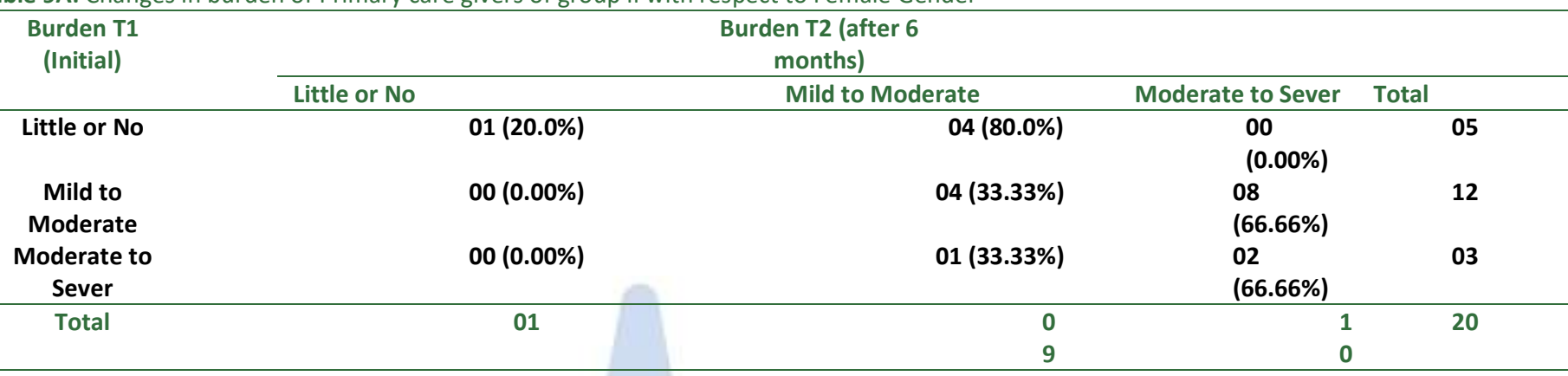

Chi-square $(\chi 2)$ test:8.14, d.f:04, P:0.08 Non-Significant

Table 9B: Changes in burden of Primary care givers of group II with respect to Male Gender

Burden T1 (Initial)
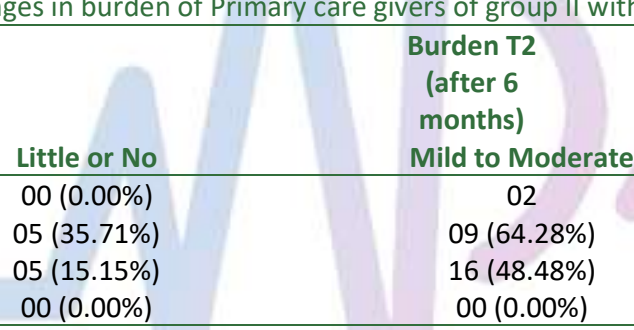

$10 \quad 27 \quad 16$

Moderate to Sever

$\begin{array}{ll}00(0.00 \%) & 02 \\ 00(0.00 \%) & 14\end{array}$

$12(36.36 \% \quad 33$

$04(100.0 \%)$

16

Chi-square (x2) test:18.69, d.f:06, P:0.005 Significant

Table 10 A: Changes in burden of Primary caregivers of Group I who were less than 40 years old

\begin{tabular}{ccccc}
\hline & \multicolumn{2}{c}{ Burden T2 (after 06 months) } & & \\
Burden T1(Initial) & Mild to Moderate & Moderate to Sever & Severe & Total \\
\hline Little or No & $\mathbf{0 2}(\mathbf{6 6 . 6 6 \% )}$ & $\mathbf{0 1}(\mathbf{3 3 . 3 3 \% )}$ & $\mathbf{0 0}(\mathbf{0 . 0 0 \% )}$ & $\mathbf{0 3}$ \\
Mild to Moderate & $\mathbf{0 2 ( 1 3 . 3 3 \% )}$ & $\mathbf{1 0}(66.66 \%)$ & $\mathbf{0 3}(\mathbf{2 0 . 0 \% )}$ & $\mathbf{1 5}$ \\
Moderate to Sever & $\mathbf{0 0 ( 0 . 0 0 \% )}$ & $\mathbf{0 8}(53.33 \%)$ & $\mathbf{0 7}(\mathbf{4 6 . 6 6 \% )}$ & $\mathbf{1 5}$ \\
\hline Total & 04 & 19 & 10 & 33 \\
\hline
\end{tabular}

Chi-square test $(\chi 2): 12.52$, d.f:04, P:0.01 Significant

Table 10 B: Changes in burden of Primary caregivers of Group I who were More than 41 years old

\begin{tabular}{ccccc}
\hline \multicolumn{5}{c}{ Burden T2 (after 06 months) } \\
\hline $\begin{array}{c}\text { Burden T1 (Initial) } \\
\text { Mild to }\end{array}$ & Mild to Moderate & Moderate to Sever & Severe & Total \\
$\begin{array}{c}\text { Moderate } \\
\text { Serate to }\end{array}$ & $02(12.5 \%)$ & $13(8.12 \%)$ & $01(6.25 \%)$ & 16 \\
\hline $\begin{array}{c}\text { Tot } \\
\text { al }\end{array}$ & $00(0.00 \%)$ & $11(42.30 \%)$ & $\begin{array}{c}15 \\
(57.69 \%)\end{array}$ & 26 \\
\hline
\end{tabular}

Chi-square test ( $\chi 2) 12.75$, d.f:02, P:0.002 Significant 
Table 11A: Changes in burden of Primary caregivers of Group II who were less than 40 years old

\begin{tabular}{|c|c|c|c|c|}
\hline \multirow[b]{2}{*}{ Burden T1 (Initial) } & \multicolumn{4}{|c|}{ Burden T2 (after 06 months) } \\
\hline & Little or No & Mild to Moderate & Moderate to Sever & Total \\
\hline No Burden & $00(0.00 \%)$ & $(100.0 \%) 00$ & $(0.00 \%)$ & 01 \\
\hline Little or No & $02(22.22 \%)$ & $07(77.77 \%)$ & $00(0.00 \%)$ & 09 \\
\hline Mild to Moderate & $02(9.52 \%)$ & $11(52.38 \%)$ & 08 (38.09\%) & 21 \\
\hline Moderate to Sever & $00(0.00 \%)$ & $00(0.00 \%)$ & $02(100.0 \%)$ & 02 \\
\hline Total & 04 & 19 & 10 & 33 \\
\hline
\end{tabular}

\begin{tabular}{ccccc}
\multicolumn{5}{c}{ Table 11B: Changes in burden of Primary caregivers of Group II who were more than 41 years old } \\
\hline \multicolumn{5}{c}{ Burden T2 (after 06 months) } \\
\hline Burden T1(Initial) & Little or No & Mild to Moderate & Moderate to Sever & Total \\
No Burden & $00(0.00 \%)$ & $01(100.0 \%)$ & $00(0.00 \%)$ & 01 \\
Little or No & $04(40.0 \%)$ & $06(60.0 \%)$ & $00(0.00 \%)$ & 10 \\
Mild to Moderate & $03(12.5 \%)$ & $09(37.5 \%)$ & $12(50.0 \%)$ & 24 \\
Moderate to Sever & $00(0.00 \%)$ & $01(20.0 \%)$ & $04(80.0 \%)$ & 05 \\
\hline Total & 07 & 17 & 16 & 40 \\
\hline
\end{tabular}

Chi-square test ( $\chi 2): 13.52$, d.f:06, P:0.03 Significant

\section{DISCUSSION}

\begin{tabular}{|c|c|c|c|c|}
\hline & $\begin{array}{l}\text { Dr Tekale J et.al. } \\
\text { (Present study) }\end{array}$ & $\begin{array}{c}\text { Abbasi Ali et. al. }{ }^{6} \\
\text { (Gloestan Univ. study) }\end{array}$ & $\begin{array}{l}\text { Mashayekhi F et.al. }{ }^{7} \\
\text { (Jiroft Univ. study) }\end{array}$ & $\begin{array}{c}\text { Jafari H et.al }{ }^{8} \\
\text { (Kermanshah Uni, study) }\end{array}$ \\
\hline Mean age \pm Sd. & $42.54 \pm(9.43)$ & $* * * * *$ & $42.11 \pm 14.78$ & $42 \pm 15$ \\
\hline Gender & $26.6 \% \mathrm{~F}, 73.3 \% 55 \mathrm{M}$ & $68.6 \% \mathrm{~F}, 31.4 \% \mathrm{M}$ & $* * * *$ & $* * * * *$ \\
\hline $\begin{array}{c}\text { Burden (severe) on care } \\
\text { givers }\end{array}$ & $34.7 \%$ & $74.2 \%$ & $72.5 \%$ & $37.4 \%$ \\
\hline
\end{tabular}

\section{SUMMARY}

Total 148 primary care givers ( 75 group I and 73 group II) were interviewed twice; $27 \%$ and $73 \%$ were males and females respectively. Mean difference of age in between group I and group II found to be non significant

\begin{tabular}{|c|c|c|c|c|c|}
\hline \multirow[t]{3}{*}{ Group I } & \multicolumn{2}{|c|}{ Burden@ First Interview } & \multicolumn{2}{|c|}{ Burden@Second Interview } & \\
\hline & Mild to Mod. & Mod. To Severe & Mod. To Severe & Sever & \\
\hline & $41.3 \%$ & $54.7 \%$ & $57.3 \%$ & $34.7 \%$ & \\
\hline \multirow[t]{2}{*}{ Group II } & Mild to Mod. & Mod. To Severe & Mild to Mod. & Mod. To Severe & \multirow{2}{*}{$\begin{array}{c}\text { Tone had serere } \\
\text { burden }\end{array}$} \\
\hline & $61.6 \%$ & $09.6 \%$ & $49.3 \%$ & $35.6 \%$ & \\
\hline
\end{tabular}

In group I; out of 41 cases of moderate to severe burden $53.65 \%$ (22) converted in to severe type of burden during 06 months of therapy; in groups II no such changes of burden were observed. $55 \%$ female; and $27.27 \%$ male primary caregivers of group 'I' had severe burden; after 6 months of treatment, the burden of majority females primary caregivers of this group changed in to severe. While no such observation has seen group II. Severe type of burden was seen more in the above 41 years old primary caregivers as compared to less than 40 years old in group I; while no such changes were observed in group II.

\section{CONCLUSION}

Present study gives following conclusions; Haemodialysis with pharmacotherapy increases the burden on primary caregivers of chronic renal failure patients; as compared to only pharmacotherapy. Females are more prone to get severe type of burden as compared to males and also their burden changes in to severe type more. As compared to 'little or no' and 'mild to moderate' type burden; moderate to severe type of burden changes more in to severe type. Primary caregivers of above 41 years showed more severe type of burden as compared to less than 40 years old. 


\section{REFERENCES}

1. Commission on Chronic illness (1956) Chronic illness in the US. Vol II, Care of the long-term patient. Cambridge, Mass, Harvard University Press.

2. Darowska-Bender M, Dykowska G, Zuk W, Milewska M, Staniszewska A. The impact of quality of life of dialysis patients with renal insufficiency. Patient Preference and Adherence 2018:12;577-83

3. Goyal E, Chaudhary S, Saldanha D. Psychiatry comorbidity in patients undergoing haemodialysis. Ind.Psychiatry J. 2018:27(2);206-212

4. Zarit SH; Zarit Burden Interview (ZBI), available on https://eprovide.mapi-trust.org/instruments/zarit-burdeninterview
5. The World Health Organisation- Five Well-Being Index (WHO-5), available on https://www.corc.uk.net/outcomeexperience-measures/the-world-health-organisation-fivewell-being-index-who-5/

6. Abbasi Ali, Asayesh H, Rahmani H, Shariati A, Hosseini SA, Rouhi G. et.al. The burden on caregivers from hemodialysis patients and related factors. Scientific Journal of Gorgan Bouyeh School of Nursing and Midwifery. 2011:8;26

7. Mashayekhi F, Sardo MR, Soltaninejad M. Relationship between depressive symptoms and Quality of Life with caregivers burden in hemodialysis patients. Int. J. Adv. Res. Biol. Sci. 2015:2(11):225-233

8. Jafari H, Ebrahimi A, Aghaei A, Khatony A. The relation between care burden and quality of life in caregivers of hemodialysis patients. BMC Nephrology. 2018;19:321

\section{Source of Support: None Declared} Conflict of Interest: None Declared 